\title{
Connecting Students and Academics Through the Arts
}

\author{
Libby V. Morris
}

Published online: 15 September 2012

(C) Springer Science+Business Media, LLC 2012

It is my belief that the foundation of a college education is the fine arts and the humanities. In the classics, philosophy, history, music and art, to name only a few of the liberal arts, we explore and seek to understand our existence in historic and contemporary terms. Through the arts, we create stories and re-enact dramas; we analyze pictures and paint new ones; we blend voices and sing new notes. The liberal arts educate our minds and our hearts so that we may engage more fully and more completely in relationships, in meaningful work, and in a better quality of life.

In recent years, as consumerism has swept across the nation and the purpose of a college education has shifted from "creating a meaningful philosophy of life" to "earning a higher income," the humanities struggled to show relevance or to have a voice at the table. Undergraduate professional programs of study have begun to dominate curricular offerings and enrollments while stressing employability and economic return on the college investment. Money has flowed into STEM education (Science, Technology, Engineering and Math), while public funding for the arts has declined in many places. Workforce development increasingly supplants the development of the "whole individual," and general education has been de-emphasized as technical courses of study and "electives" serving the majors play a larger role in general education. Now, I do paint (forgive my pun) with a broad brush. Certainly there are many private liberal arts colleges across the nation that embrace and promote the liberal arts throughout the undergraduate curriculum, but their impact is small when judged by the sheer numbers of students attending the comprehensive and research institutions nationwide.

So, I find it particularly heartening to see many leading research universities re-emphasizing the central place of the liberal arts and humanities in a college education with the formation of task forces and the issuance of new (or revised) strategic plans for the arts. For example, Harvard issued the Report of the Task Force on the Arts in 2008; and The University of North Carolina Board of Trustees created Art@Carolina: Explore, innovate, celebrate in 2011; Emory University penned an Arts Blueprint in 2010; and The Arts at Virginia Tech was issued in 2010.

L. V. Morris $(\bowtie)$

Institute of Higher Education, University of Georgia, 102 Meigs Hall, Athens, GA 30602-6772, USA

e-mail: lvmorris@uga.edu 
These reports and numerous articles in Liberal Education by the Association of American Colleges and Universities stress the centrality of the arts in the education of the nation's engineers, scientists, lawyers, and teachers. These reports advocate the role of the arts in teaching creativity, in understanding multiple cultures, in embracing diversity, in thinking globally, and in shaping one's identity across the life span. It is said that we know our society and others, across the centuries, by their arts--visual, performing, literary--from poetry to paintings to architecture. If our children are not educated in the arts and they do not support the arts, what will they conserve and create for future generations?

The University of Georgia, since its founding as the first publicly-chartered university in 1785, has exhibited a strong commitment to the arts in the curriculum, in programming and exhibitions, and its structures. Over the last 15 years, UGA has invested substantially in funding new buildings for the arts, including the Hugh Hodgson School of Music, the Lamar Dodd School of Art, the world-class Performing Arts Center, and a newly expanded Georgia Museum of Art. Only last year, the historic fine arts center was restored, top to bottom, in a magnificent feat of architectural sensitivity and usability.

This investment in teaching and research spaces and performance and exhibition venues begged the question of how UGA could more effectively leverage these facilities to support art programs and artists on our campus. The time was right for a campus wide Arts Council. Thus, in fall semester 2011, we convened the first meeting of the directors and chairs of the visual, performing, and literary arts to explore their issues and priorities and to examine how we could collectively raise the visibility and prominence of the arts on the campus and beyond. With support from the Office of the Provost, the Arts Council now meets monthly, as do members of their respective staffs with responsibilities for marketing and public relations. The energy is palpable! In fact, a couple of deans have "complained" (not in the arts I might add) that they have not been included! Deans are clever; they can see an initiative gaining momentum!

The Council aims to raise awareness of the broad range of arts programs and events offered by units, faculty, and students at UGA. We want to showcase the fun side and the scholarly side of the arts and to encourage people, especially those who have never done so, to visit the Georgia Museum of Art or to attend a concert at the Performing Arts Center or to go to a theater or dance performance in the Fine Arts Building or the New Dance Theatre. We want to make sure students and others are aware that UGA is home to a nationally acclaimed literary magazine in The Georgia Review, to an award-winning UGA Press, and to a brand new Special Collections Library, which features over 115,000 square feet at a cost of $\$ 46$ million, all to preserve the state and nation's cultural heritage.

As if building a network, designing promotional materials, and creating new media outlets were not enough, the Council is now planning a 9-day arts festival, Spotlight on the Arts, in the late fall. Returning to the campus for the week will be U.S. poet laureate and UGA graduate, Natasha Tretheway, for a presentation and classroom visits. If we are not totally exhausted after more than a week of celebration of the arts, we will begin the UGA strategic plan for the arts. I guess you can tell that I am excited about all of this. To learn more about the Arts at UGA, visit our website at http://arts.uga.edu/. I hope that this short piece has encouraged you to think more deliberately about the role of the arts on your campus and that you will visit or take your students to an arts event soon.

In the spirit of Innovative Higher Education, Kay Gillespie and I welcome your research on the arts to add to our understanding of the role of the arts in higher education. 